10

\title{
Фотоотклик в мультислойном графене при прохождении поверхностной акустической волны
}

\author{
(C) О.В. Кононенко, Е.В. Емелин, В.Н. Матвеев, Д.В. Рощупкин
}

Институт проблем технологии микроэлектроники и особочистых материалов РАН, Черноголовка, Московская обл., Россия

E-mail: oleg@iptm.ru

Поступило в Редакцию 28 октября 2019г.

В окончательной редакции 28 октября 2019 г.

Принято к публикации 28 ноября 2019г.

Исследован фотоотклик в мультислойном графене на кристалле ниобата лития $\left(\mathrm{LiNbO}_{3}\right)$ в условиях приложенного к графену электрического потенциала и пропускания поверхностной акустической волны. Показано, что акустоэлектрический ток в графене при облучении светом либо возрастает, либо уменьшается в зависимости от полярности приложенного к графену потенциала. Поверхностная акустическая волна вызывает появление в графене периодической решетки зарядов, усиливающей взаимодействие с падающим светом, что приводит к увеличению фотоотклика.

Ключевые слова: графен, поверхностная акустическая волна, акустоэлектрический ток, фотоотклик.

DOI: 10.21883/PJTF.2020.05.49102.18087

Акустоэлектронные устройства активно используются в качестве датчиков физических величин, принцип работы которых основан на изменении резонансных частот возбуждения акустических волн в конкретных физических условиях (давление, ускорение, температура, влажность и др.). Недавно в работах $[1,2]$ сообщалось о датчиках влажности и газовых датчиках на основе оксида графена и графена, в которых использовались поверхностные акустические волны (ПАВ). В последнее время взаимодействие ПАВ с носителями заряда в графене вызывает интерес исследователей. Взаимодействие электрических зарядов и ПАВ приводит к появлению акустоэлектрического (АЭ) тока в графене [3-7]. Была также показана возможность управления акустической волной в условиях приложенного к пленке графена электрического потенциала [8] и продемонстрирован фотоотклик в графене и графеновых нанолентах в условиях протекания АЭ-тока $[9,10]$. В настоящей работе исследуется фотоотклик в пленке мультислойного графена в условиях приложения к пленке электрического потенциала различной полярности и взаимодействия с ПАВ.

Образцы для исследования фотоотклика изготавливались следующим образом. На поверхности $Y Z$-среза кристалла $\mathrm{LiNbO}_{3}$ для возбуждения и регистрации ПАВ с длиной волны $30 \mu \mathrm{m}$ на резонансной частоте $114.7 \mathrm{MHz}$ методом фотолитографии и электроннолучевого осаждения были изготовлены алюминиевые встречно-штыревые преобразователи (ВШП). ВШП состояли из 50 пар штырей. Пленки графена были синтезированы методом химического парофазного осаждения при низком давлении с однократным напуском ацетилена. В качестве катализатора использовались пленки чистого никеля толщиной $0.3 \mu \mathrm{m}$, напыленные на пластины окисленного кремния методом лазерного импульсного осаждения. После синтеза на поверхность пленок никеля с выращенным графеном был нанесен слой полиметилметакрилата (РММА) толщиной $0.8 \mu \mathrm{m}$, который в дальнейшем служил поддерживающей пленкой для графена. Образцы погружались в однопроцентный водный раствор соляной кислоты для растворения никелевой пленки. В процессе травления графен вместе с поддерживающей пленкой РММА отделялся от подложки. После полного растворения никеля графен с РММА промывался в деионизованной воде и переносился на поверхность кристаллов $\mathrm{LiNbO}_{3}$ между двумя ВШП. РММА удалялся с поверхности графена растворением в ацетоне.

Для характеризации пленок графена использовалась спектроскопия комбинационного рассеяния. Спектры измерялись в 8-10 разных точках на поверхности образцов с помощью рамановского микроскопа SENTERRA Bruker c длиной волны лазера $488 \mathrm{~nm}$. Диаметр лазерного пучка был порядка $1 \mu \mathrm{m}$. На рис. 1 приведен типичный спектр комбинационного рассеяния, полученный для графеновой пленки. В спектре видны четкие пики $G$ и $2 D$, указывающие на наличие графена. Слабый пик $D$ свидетельствует о низком содержании дефектов. Отношение интенсивностей пиков $2 D$ и $G$, равное 0.75 , и ширина на полувысоте пика $2 D$, равная $65 \mathrm{~cm}^{-1}$, указывают на то, что пленка содержит 3-4 монослоя графена.

Для исследования электрических свойств графена в условиях распространения ПАВ методом электроннолучевой литографии на поверхности пленки графена были сформированы два платиновых электрода. Расстояние между электродами составляет $\sim 3 \mathrm{~mm}$. Один электрод находился ближе к ВШП, генерирующему ПАВ, другой - дальше от него. Измерения проводились 


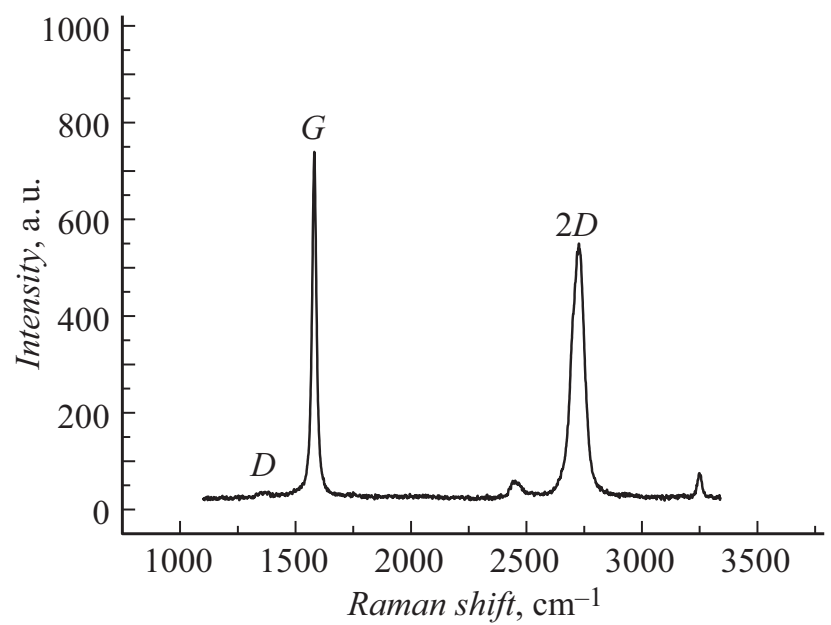

Рис. 1. Типичный спектр комбинационного рассеяния пленки графена, выращенной на пленке никелевого катализатора.

с помощью источника-измерителя Keithley 2400. Вольтамперные характеристики, измеренные между электродами, показали омическое поведение, что указывает на омичность контактов к графену.

В качестве источника света использовалась ртутная лампа высокого давления, излучавшая свет в диапазоне примерно $300 \mathrm{~nm}$. УФ-диапазон света был выбран из-за того, что монослой графена поглощает в видимом диапазоне только $2.3 \%$, а в УФ-диапазоне - около $6 \%$.

Перед тем как возбуждать в образцах ПАВ, в графеновой пленке был исследован фотоотклик при приложении к электродам электрического потенциала $5 \mathrm{mV}$. Независимо от полярности прикладываемого потенциала в пленках наблюдался фототок. На рис. 2, $a$ и $b$ кривые 1 показывают сопротивления пленки графена при закрытой и открытой заслонке, регулирующей световой поток. При облучении светом ток в графене увеличивался на 3\%. При генерации ПАВ в графене наблюдается отрицательный АЭ-ток, вызванный захватом электронов бегущей акустической волной. Величина АЭ-тока зависит от амплитуды волны. Чем выше амплитуда, тем больше ток. Это обусловлено тем, что с увеличением амплитуды ПАВ из-за пьезоэлектрического эффекта происходит увеличение потенциала в минимумах и максимумах акустической волны, что соответственно приводит к увеличению сбора зарядов в пленке графена и их переносу акустической волной между электродами [6]. При облучении светом в условиях бегущей ПАВ ток в графене ведет себя иначе, чем при ее отсутствии. Изменение тока при облучении светом примерно в 8 раз больше и достигает примерно $24 \%$. Однако величина тока зависит от полярности электрического потенциала, приложенного к графену. Если полярность потенциала, приложенного к электродам, такова, что электроны движутся в направлении бегущей ПАВ, то облучение светом приводит к увеличению тока в графене и сопротивление графена падает (рис. 2,a, кривая 2).
Если же полярность приложенного потенциала такова, что электроны в графене движутся навстречу бегущей ПАВ, то облучение светом приводит к уменьшению тока в графене и сопротивление графена увеличивается (рис. 2, $b$, кривая 2).

В работе [8] было показано, что электрический потенциал, приложенный к графену, оказывает влияние на амплитуду бегущей ПАВ. Электрический потенциал, вызывающий ток электронов в направлении ПАВ, приводит к усилению ПАВ и увеличению ее амплитуды. Если же приложенный потенциал направляет электроны в графене навстречу ПАВ, то происходит ее ослабление и уменьшение амплитуды. От амплитуды ПАВ зависит величина АЭ-тока. Поэтому фототок, возникающий в графене при облучении светом, либо усиливает, либо ослабляет амплитуду акустической волны (в зависимости от полярности приложенного электрического потенциала) и соответственно либо усиливает, либо ослабляет АЭ-ток в графене. Таким образом, обнаруженный нами положительный и отрицательный акустоэлектрический
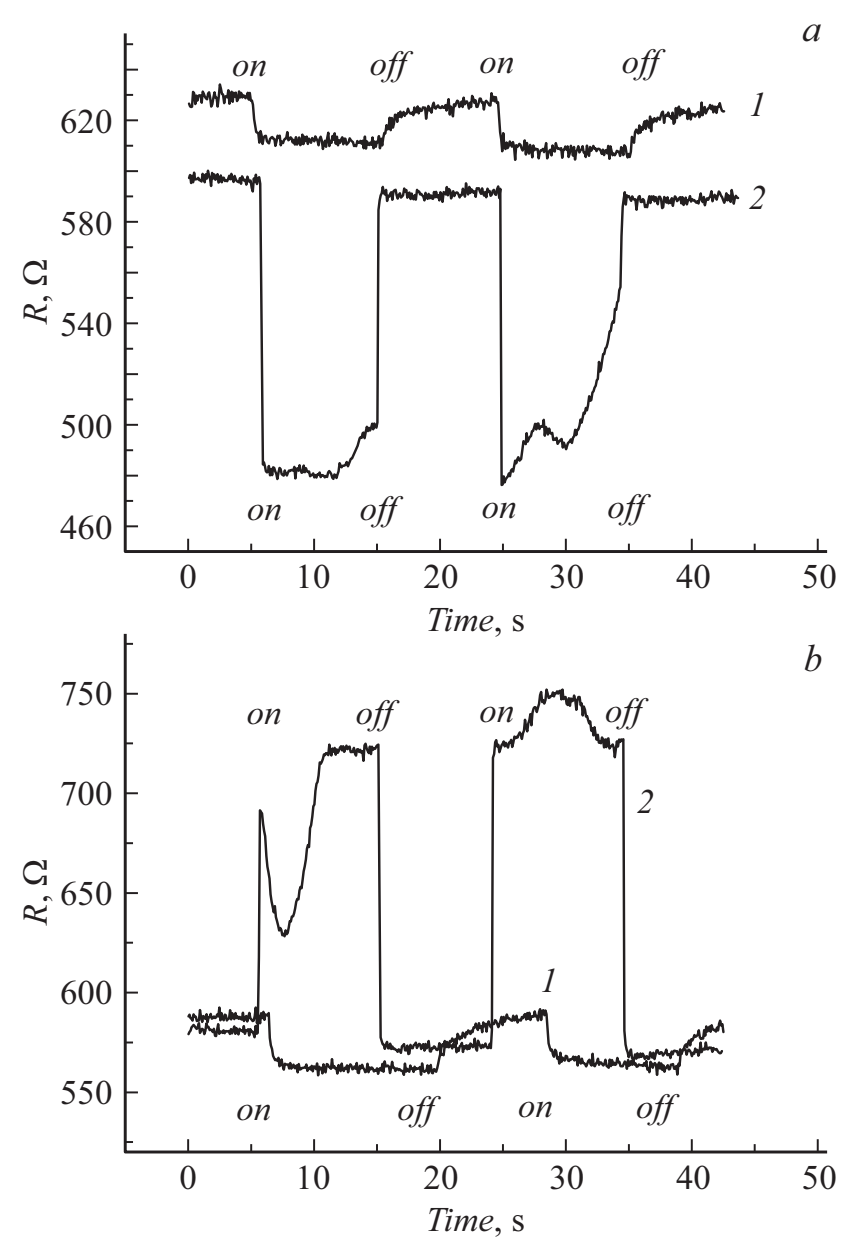

Рис. 2. Изменение сопротивления пленки графена при освещении УФ-излучением без ПАВ (1) и при прохождении ПАВ (2). Данные, представленные на частях $a$ и $b$, отличаются полярностью приложенного к графену электрического напряжения (см. текст). 

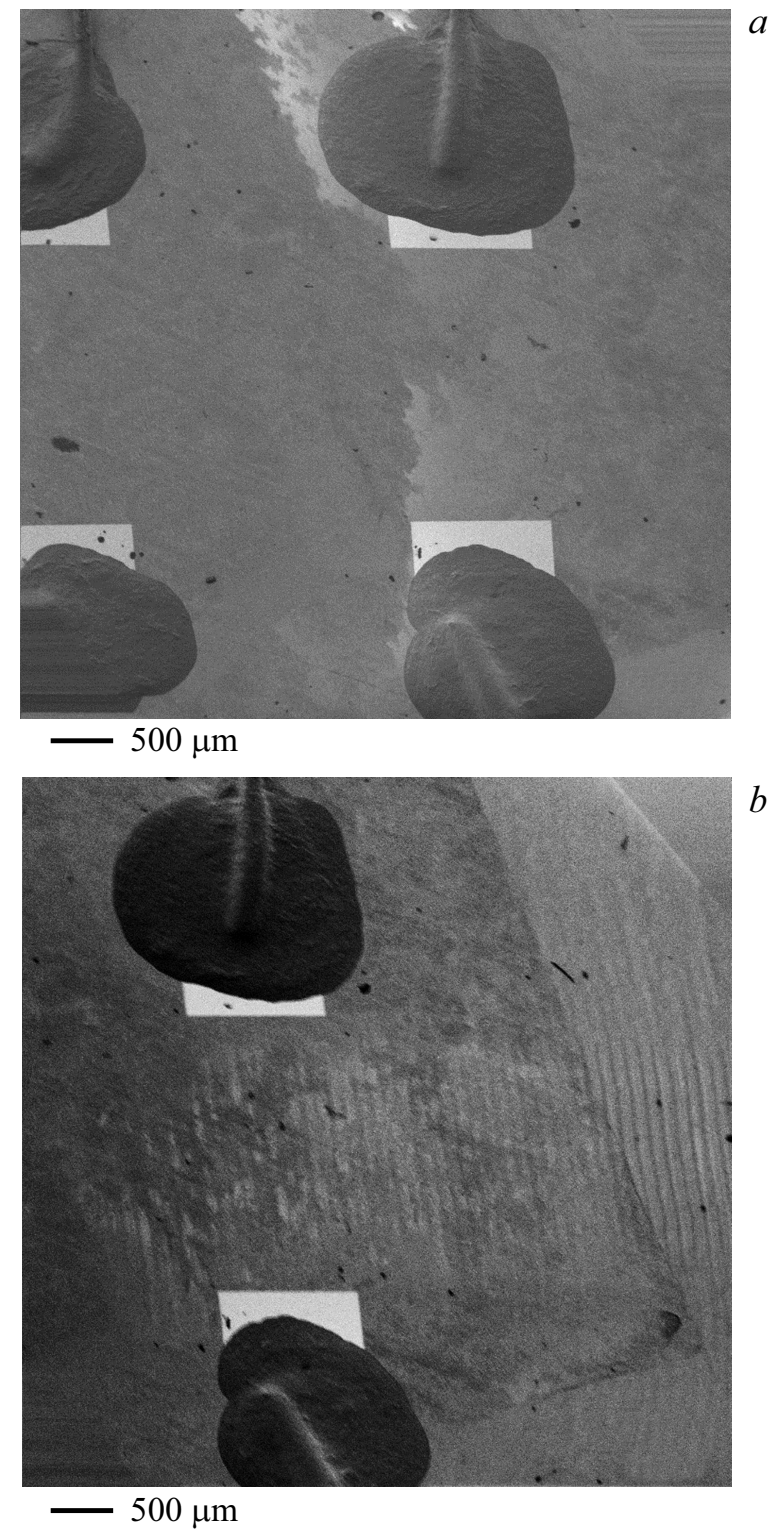

Рис. 3. СЭМ-изображения пленки графена на кристалле ниобата лития без ПАВ $(a)$ и с бегущей ПАВ $(b)$.

фотоотклик связан с увеличением или уменьшением амплитуды ПАВ в зависимости от полярности электрического потенциала, приложенного к графену.

Усиление фотоотклика в графене при прохождении ПАВ связано, по-видимому, с плазмонными колебаниями, возникновению которых способствует ПАВ. В работе [11] было показано, что сочетание графена с плазмонными наноструктурами позволяет увеличить эффективность фотоприемников на основе графена в 20 раз благодаря эффективной концентрации поля в области $p-n$-перехода. Такие $p-n$-переходы часто возникают вблизи металлических контактов из-за разницы в работах выхода металла и графена. В работах $[12,13]$ было показано, что под действием падающего электромагнитного поля в графене, лежащем на подложке, можно эффективно возбуждать поверхностные плазмоны. Если в графене с помощью изгибной волны, например ПАВ, возбудить упругие колебания, то они действуют как решетка, которая позволяет электромагнитному полю связываться с распространяющимися в графене плазмонами. По расчетам [12] можно связать до 45\% энергии света (в отличие от $2 \%$ для немодулированного графена).

Для исследования процесса распространения ПАВ в графене на пьезоэлектрическом кристалле можно использовать метод сканирующей электронной микроскопии. Метод сканирующей электронной микроскопии позволяет визуализировать распространение акустических волн в режиме регистрации низкоэнергетических вторичных электронов, чувствительных к электрическим полям, сопровождающим распространение ПАВ в пьезоэлектриках $[14,15]$. Визуализация процесса распространения ПАВ осуществлялась в сканирующем электронном микроскопе (СЭМ) при ускоряющем напряжении $E=1 \mathrm{kV}$ и токе электронного зонда $I=0.3 \mathrm{nA}$. На рис. 3 показаны СЭМ-изображения пленки графена на поверхности кристалла $\mathrm{LiNbO}_{3}$. В отсутствие ПАВ контраст графеновой пленки однороден (рис. 3,a). При прохождении ПАВ на поверхности и $\mathrm{LiNbO}_{3}$, и графена проявляется периодическая структура (рис. $3, b$ ), соответствующая длине волны ПАВ, связанная с различием потенциалов в минимумах и максимумах акустической волны. Темный контраст на изображении соответствует положительному заряду, а светлый - отрицательному. Таким образом, наблюдаемая в графене периодическая решетка зарядов, по-видимому, является причиной усиления взаимодействия с падающим светом и увеличения фотоотклика в графене.

\section{Финансирование работы}

Работа выполнена при финансовой поддержке Российского фонда фундаментальных исследований (грант № 16-29-06306).

\section{Конфликт интересов}

Авторы заявляют, что у них нет конфликта интересов.

\section{Список литературы}

[1] Xuan W., He M., Meng N., He X., Wang W., Chen J., Shi T., Hasan T., Xu Z., Xu Y., Luo J.K. // Sci. Rep. 2014. V. 4. P. 7206. DOI: $10.1038 /$ srep07206

[2] Whitehead E.F., Chick E.M., Bandhu L., Lawton L.M., Nash G.R. // Appl. Phys. Lett. 2013. V. 103. P. 063110. DOI: $10.1063 / 1.4818465$

[3] Miseikis V., Cunningham J.E., Saeed K., O'Rorke R., Davies A.G. // Appl. Phys. Lett. 2012. V. 100. P. 133105. DOI: $10.1063 / 1.3697403$

[4] Bandhu L., Lawton L.M., Nash G.R. // Appl. Phys. Lett. 2013. V. 103, P. 133101. DOI: 10.1063/1.4822121 
[5] Bandhu L., Nash G.R. // Appl. Phys. Lett. 2014. V. 105. P. 263106. DOI: $10.1063 / 1.4905222$

[6] Roshchupkin D., Ortega L., Zizak I., Plotitcyna O., Matveev V., Kononenko O., Emelin E., Erko A., Tynyshtykbayev K., Irzhak D., Insepov Z. // J. Appl. Phys. 2015. V. 118. P. 104901. DOI: $10.1063 / 1.4930050$

[7] Hernandez-Minguez A., Tahraoui A., Lopes J.M.J., Santos P.V. // Appl. Phys. Lett. 2016. V. 108. P. 193502. DOI: $10.1063 / 1.4949756$

[8] Insepov Z., Emelin E., Kononenko O., Roshchupkin D.V., Tnyshtykbayev K.B., Baigarin K.A. // Appl. Phys. Lett. 2015. V. 106. P. 023505. DOI: $10.1063 / 1.4906033$

[9] Poole T., Bandhu L., Nash G.R. // Appl. Phys. Lett. 2015. V. 106. P. 133107. DOI: $10.1063 / 1.4916940$

[10] Poole T., Nash G.R. // J. Phys. D: Appl. Phys. 2018. V. 51. P. 154001. DOI: 10.1088/1361-6463/aab3ec

[11] Echtermeyer T.J., Britnell L., Jasnos P.K., Lombardo A., Gorbachev R.V., Grigorenko A.N., Geim A.K., Ferrari A.C., Novoselov K.S. // Nature Commun. 2011. V. 2. P. 458. DOI: $10.1038 /$ ncomms1464

[12] Farhat M., Guenneau S., Bagci H. // Phys. Rev. Lett. 2013. V. 111. P. 237404. DOI: 10.1103/PhysRevLett.111.237404

[13] Schiefele J., Pedros J., Sols F., Calle F., Guinea F. // Phys. Rev. Lett. 2013. V. 111. P. 237405. DOI: 10.1103/PhysRevLett.111.237405

[14] Tanski W.J., Wittels N.D. // Appl. Phys. Lett. 1979. V. 34. P. 537-539. DOI: $10.1063 / 1.90878$

[15] Roshchupkin D.V., Brunel M., Tucoulou R., Bigler E., Sorokin N.G. // Appl. Phys. Lett. 1994. V. 64. P. 164-165. DOI: $10.1063 / 1.111552$ 